\title{
The hidden curriculum in under graduate medical education in Bangladesh: medical students' perception
}

\author{
Dr. Tahmina Nargis ${ }^{1}$, Prof. Dr Md Humayun Kabir Talukder ${ }^{2}$, Dr, Kazi khairul Alam ${ }^{3}$
}

\begin{abstract}
This descriptive cross sectional study was conducted among 386 students of $3^{\text {rd }}$ phase of selected 2 government and 2 non government medical colleges of Bangladesh in 2013. The objective of the study was to find out the perceptions of the students regarding hidden curriculum in undergraduate medical education. Sampling technique was convenient. A self administered structured questionnaire was used and it consisting of 43 items in relation to hidden curriculum in the likert scale. Perceptions of the respondents were positive about 27 items that is the issues on these item areas were satisfactory in their institutes. Mean scores of these items were more than 3 for each. On the contrary perceptions of the respondents were negative for 16 items that is the issues on these item areas were not satisfactory in their institutes. Mean scores of these items were less than 3 for each. The study result can be used to sensitize and aware the concerned teachers/ authorities for valuing the importance of hidden curriculum and address the issues accordingly.
\end{abstract}

Key Words: Hidden, Curriculum, under graduate, perception

\section{Introduction and Background}

The curriculum is a sophisticated blend of educational strategies, course content, learning outcomes, educational experiences, assessments, the educational environments and the individual students learning styles, personal time table and programmme of work (Harden 2001 b). The curriculum is seen as covering not only what is taught but also how it is taught and learned, and how the learning is managed and overall learning environment (Harden 1986).

No account of the curriculum content would be complete without reference to the concept of the hidden curriculum. The 'declared' curriculum is the curriculum as set out in the institution's documents. The 'taught' curriculum is what happens in practice. The 'learned' curriculum is what is learned by the student. The 'hidden' curriculum is the informal learning in which students engage and which is unrelated to what is taught (Harden 2005). Hidden curriculum is the set of influences that function at the level of organizational structure and culture including, for example implicit rules to survive the institute such as customs, rituals and taken for granted aspects (Lempp 2004). The message of hidden curriculum usually deals with attitude, values, beliefs and behaviors. There are numerous such messages conveyed indirectly. The culture of medicine has a profound influence on the behaviours of the practicing physicians, because it shapes basic assumptions about what are "acceptable" and what are "unacceptable" medical practices (Hafferty 1998). Simple things like how to address

'Asst. Prof., Medical Education, Centre for Medical Education, Dhaka

${ }^{2}$ Professor, Curriculum Development \& Evaluation,

Centre for Medical Education

${ }^{3}$ Asstt. prof., Medical Education, Centre for Medical Education

Address of correspondence: Dr. Tahmina Nargis

Asst. Prof., Medical Education, Centre for Medical Education, Dhaka

E-mail: tahminacme@gmail.com patients, relatives and other professionals in health care team is rarely taught in formal teaching. Generations of doctors have learned these through informal and hidden curriculum. The impact of hidden and informal curriculum on the medical profession is huge (kommalage 2011). Learning through hidden curriculum is a powerful common experience for medical students, and the messages conveyed by the hidden curriculum are culturally influenced. Discrepancies between the formal and the hidden curriculum challenge students with distressing emotional and ethical dilemmas (Lamiani et al.2011).

The teacher or facilitator is one of the most powerful components in the educational environment. The teacher's actions, attitudes (as evidenced by tone of voice and comments made), enthusiasm, and interest in the subject will affect learner indirectly. The capacity for subliminal message is enormous. In real life setting the dual role of a teacher and clinician can be complicated. The students will be closely observing the clinician, picking up the hidden messages about clinical practice (Hutchinson 2003). Hidden curriculum is in operation all times and conveys unspoken message to students about values, norms, attitudes, principles and ethics (Hafferty 1998). Exposure to the hidden curriculum begins in the preclinical learning environments with gradual erosion of professionalism ideals. The strongest impact of hidden curriculum is found generally in the clinical learning environments (Chuang et al. 2010). Role modeling is a powerful teaching tool for passing on the knowledge, skills, and values of the medical profession, but its net effect on the students is often negative rather than positive .Role models do not function only at the bedside, in the clinic, or in the office. Role models in medicine fulfill their roles in virtually any situation in which a student can observe a clinical teacher. Teachers need to be aware of the conscious and unconscious components of learning from role modeling, so that the net effect of the

Bangladesh Journal of Medical Education 2013;4(1):20-24. (C) 2013 Nargis et al., publisher and licensee Association for Medical Education. This is an Open Access article which permits unrestricted non-commercial use, provided the original work is properly cited. 
process is positive (Cruess et al.2008) Identifying, extracting and analyzing elements that comprises the hidden curriculum are definitely challenging. There are no established methodologies with which to categorize and document the components and contents of the hidden curriculum and assess it (Tekian 2009).

As the students tend to internalize and perpetuate the patterns of behavior and values that surround them, it becomes particularly relevant for medical educators to uncover the messages transmitted through the hidden curriculum (Lamiani et al.2011).

\section{Methods and materials}

This cross sectional descriptive study was conducted in conveniently selected 2 govt. \& 2 non government Medical Colleges of Bangladesh among 386 students of $3^{\text {rd }}$ phase who were Bangladeshi and willing to participate in this study as respondents and present in the lecture class during data collection. A self administered structured questionnaire was prepared in Bengali for data collection. Literature were searched and consulted with medical educationist to take input for preparing questionnaire. Few items were taken from the Dundee ready educational environment measure (DREEM) instrument (Abraham et al. 2008). Likert scale was used to measure responses of the respondents on each item. Scores was given to the scale as: strongly agree $=\mathbf{5}$, agree $=4$, undecided $=3$, disagree $=2$, strongly disagree $=1$. There were forty three items in the questionnaire among those four items were reverse scored for analysis. SPSS programme was used for analysis of data. Accordingly Means and standard deviations of the scores of the responses were presented in the tables.

\section{Interpretation of the mean score was as:}

When mean score was -

$>4-5$ - situation of the item areas were very satisfactory

$>3-4$ - situation of the item areas were Satisfactory

$>2-3$ - situation of the item areas not satisfactory

1-2, situation of the item areas were poor

Prior permission from the concerned authority was taken in time. Questionnaire was anonymous. Medical colleges and respondents were selected conveniently. Therefore generalization of the study findings cannot be made. Only the existence of hidden curriculum is identified in these medical colleges from students' opinions.

\section{Results}

Out of 386 student, 227(59) were female and 159(41) male.

Table Mean scores and standard deviations of opinion of the students regarding the statements in relation to the hidden curriculum in their institutes

\begin{tabular}{|l|c|c|}
\hline Statements in relation to relationship of the teachers with the students, staffs & Mean score and \pm SD & Total \\
\hline Relationship between teachers and students is good. & $3.33( \pm 1.05)$ & 383 \\
\hline Teachers provide guidance and are cooperative when the students are in stress. & $2.66 \pm 1.28$ & 386 \\
\hline Teachers provide advice and counsel to students when they need. & $3.24 \pm 1.22$ & 382 \\
\hline Never any teacher insults students in front of patients or others in the class or ward. & $2.17 \pm 1.21$ & 386 \\
\hline Teachers are never biased to students according to their family status. & $3.24 \pm 1.45$ & 383 \\
\hline Teachers are never biased to students according to their gender. & $3.09 \pm 1.42$ & 385 \\
\hline Teachers are never biased to students according to their religion. & $4.04 \pm 1.09$ & 386 \\
\hline Teachers are never biased to students due to any other reasons. & $3.04 \pm 1.36$ & 38 \\
\hline Never doctors / teachers insult staffs in front of patients and others in the class or ward. & $2.95 \pm 1.29$ & 386 \\
\hline Never any teacher becomes angry in the class. & $2.17 \pm 1.03$ & 382 \\
\hline Somestudents make teachers annoyed and excited. & $2.23 \pm 1.08$ & 386 \\
\hline $\begin{array}{l}\text { Statements in relation to relationship and interaction of the teachers/doctors with } \\
\text { the patients and their attendants }\end{array}$ & & $3.14 \pm 1.24$ \\
\hline Doctors always behaved well with the patients & $2.82 \pm 1.23$ & 386 \\
\hline Doctors always behaved well with the patients' attendants & $3.24 \pm 1.30$ & 386 \\
\hline $\begin{array}{l}\text { All doctors behave equally with the patients. (Never biased to patients according to } \\
\text { social status/religion/gender) }\end{array}$ & $3.45 \pm 1.14$ & 384 \\
\hline Doctors are patient with the patients in the hospital. & $2.29 \pm 1.07$ & \\
\hline Staffs always behave well with the patients /attendants & & 386 \\
\hline
\end{tabular}

Bangladesh Journal of Medical Education 2013;4(1):20-24. 


\begin{tabular}{|c|c|c|}
\hline $\begin{array}{l}\text { Statements in relation to the relations among the teachers and among staffs, } \\
\text { among students and students with staffs }\end{array}$ & Mean score and \pm SD & Total \\
\hline Relationship among teachers is good & $2.98 \pm 1.09$ & 383 \\
\hline Relationship among students is good & $2.93 \pm 1.24$ & 382 \\
\hline Relationship among staffs is good & $3.02 \pm 1.04$ & 383 \\
\hline I am helped by senior students always when I need & $3.56 \pm 1.23$ & 383 \\
\hline In this institute I have good friends & $4.32 \pm 1.03$ & 386 \\
\hline In this institute I never feel loneliness & $3.53 \pm 1.41$ & 385 \\
\hline In this institute my overall social life is fine. & $3.54 \pm 1.20$ & 385 \\
\hline There is mutual trust between team members during work in the hospital. & $3.31 \pm .98$ & 384 \\
\hline There is mutual respect between team members during work in the hospital. & $3.32 \pm 1.01$ & 385 \\
\hline Staffs always behave well with the students & $2.63 \pm 1.25$ & 381 \\
\hline \multicolumn{3}{|l|}{$\begin{array}{l}\text { Statements in relation to quality of teaching in terms of hidden curriculum in their } \\
\text { institute }\end{array}$} \\
\hline I am interested to attend the class. & $3.09 \pm 1.32$ & 384 \\
\hline Teachers always take lecture class according to routine. & $4.06 \pm 1.11$ & 386 \\
\hline Teachers always take class in the ward according to routine. & $3.67 \pm 1.23$ & 386 \\
\hline Teachers are always sincere in teaching & $3.57 \pm 1.17$ & 380 \\
\hline Teachers are authoritarian. & $2.16 \pm 1.16$ & 385 \\
\hline Teaching time is used properly. & $3.62 \pm 1.15$ & 386 \\
\hline Atmosphere is relaxed in all lecture classes. & $2.72 \pm 1.19$ & 384 \\
\hline Atmosphere is relaxed in classes in ward. & $2.81 \pm 1.19$ & 384 \\
\hline There are differences in educational environment of different departments. & $1.54 \pm .78$ & 386 \\
\hline I have learned enough about empathy. & $3.75 \pm 1.01$ & 385 \\
\hline I have become more patience after coming in this institute. & $3.88 \pm 1.11$ & 384 \\
\hline My communication skills with patients have improved. & $4.05 \pm .88)$ & 385 \\
\hline I have become more disciplined after coming in this institute. & $3.55 \pm 1.17$ & 385 \\
\hline Inever feel courage to asked question in classes when I do not understand. & $2.20 \pm 1.21$ & 382 \\
\hline \multicolumn{3}{|l|}{$\begin{array}{l}\text { Statements in relation to perceptions of the students' regarding teachers as a role } \\
\text { model }\end{array}$} \\
\hline $\begin{array}{l}\text { Each teacher in this institute is a positive role model. (Their principle, ideal, skills of } \\
\text { patient care, work style, could be followed.) }\end{array}$ & $2.97 \pm 1.25$ & 386 \\
\hline The role of a teacher as a role model is crucial for students to be a good doctor. & $4.71 \pm .60$ & 386 \\
\hline $\begin{array}{l}\text { I have been learning ethical issues in patient care by observing the behavior of } \\
\text { teachers. }\end{array}$ & $3.85 \pm .96$ & 386 \\
\hline
\end{tabular}

\section{Reversed scored items were written in italic in the table}

Table presents the mean scores of opinion of the students regarding the statements in relation to the hidden curriculum in their institutes. There were 43 items in relation to hidden curriculum. Perceptions of the respondents were positive about 27 items that is the issues on these item areas were satisfactory in their institutes. Mean scores of these items were more than 3 for each. These items were: Relationship between teachers and students is good; Teachers provide advice and counsel to students when they need; Teachers are never biased to students according to their family statuses; Teachers are never biased to students according to their gender; Teachers are never biased to students according to their religion; Teachers are never biased to students due to any other reasons; Doctors

Bangladesh Journal of Medical Education 2013;4(1):20-24. 
always behaved well with the patients; All doctors behave equally with the patients; Doctors are patient with the patients in the hospital; Relationship among staffs is good; I am helped by senior students always when I need; In this institute I have good friends; in this institute I never feel loneliness; In this institute my overall social life is fine; There is mutual trust between team members during work in the hospital; There is mutual respect between team members during work in the hospital; I am interested to attend the class; Teachers always take lecture class according to routine; Teachers always take class in the ward according to routine; Teachers are always sincere in teaching; Teaching time is used properly; I have learned enough about empathy; I have become more patience after coming in this institute; My communication skills with patients have improved; I have become more disciplined after coming in this institute; The role of a teacher as a role model is crucial for students to be a good doctor'. I have been learning ethical issues in patient care by observing the behavior of teacher'.

On the contrary perceptions of the respondents were negative for 16 items that is the issues on these item areas were not satisfactory in their institutes. Mean scores of these items were less than 3 for each. These items were: Teachers provide guidance and are cooperative when the students are in stress; Never any teacher insults students in front of patients or others in the class; Never doctors / teachers insult staffs in front of patients and others in the class; Never any teacher becomes angry in the classes; Some students make teachers annoyed and excited; Doctors always behaved well with the patients' attendants;

Staffs always behave well with the patients /attendants; Relationship among teachers is good; Relationship among students is good; Staffs always behave well with the students; Teachers are authoritarian; Atmosphere is relaxed in all lecture classes; Atmosphere is relaxed in classes in ward; there are differences in educational environment of different departments; I never feel courage to asked question in classes when I do not understand; Each teacher in this institute is a positive role model (Their principle, ideal, skills of patient care, work style, could be followed);

\section{Discussion}

Relationship of the teachers with the students, staffs: It was found in this study that the respondents' perception was positive about the item 'the relationship between teachers and students is good'. Mean score of the responses was 3.33. This indicates that the relationship between teachers and students was satisfactory. Haidet (2006) concluded in his article that the relationship we form with our students will be key sources of experiences that those students will draw upon when they find themselves in the role of a teacher with their patients. Mean score of the responses was 2.66 regarding the item 'Teachers provide guidance and are cooperative when the students are in stresses'. Respondents' perception was negative about this aspect. In studies conducted by Chandratilake (2009) and
Abraham (2008), it was found that the students' perception was negative with a median score of 2 or less for the item 'there is a good support system for students who get stressed'. Respondents' perception was negative with mean score of the responses was 2.17 on the item 'never any teachers insult students in front of the patients and others in the class or ward'. Similar finding was found out by Chandratilake (2009), in his study median score for the item 'Teachers ridicule students' was 2. Most of the students perceived that the teachers were never biased to students according to students' family status, gender, religion and due to any other reason and for each of the variables mean score was more than 3 .

This study also revealed that most of the students perceived that doctors and teachers insult staffs in front of patients and others in the class or ward with a mean score of 2.95 for the responses. Respondents' perception was negative about the statement 'never any teacher become angry in the classes' and mean score for this item was 2.17. Similar finding was found out by Chandratilake (2009), in his study, the students' perception was negative with a median score of 2 for the item 'teachers get angry in classes'. More than three fourth of the respondents perceived that some students make teachers annoyed and excited, for this item mean score of responses was 2.23. Respondents' perception was negative about this aspect. Chandratilake (2009) found that the students perception was negative with a median score 2 for the item 'teachers are irritated by students'.

\section{Relationship and interaction of the teachers/ doctors and staffs with the patients and their attendants:}

This study revealed that about half of the respondents perceived that doctors always behave well with the patients and all doctors behave equally with the patients for this item mean score of responses was more than 3. Lamiani (2011) found in his study the power differentials between physicians and patients and variable respect for patients. Respondents' perception was negative on the items 'that doctors always behave well with the patients' attendants', and 'staffs always behave well with the patients and attendants', and mean score was less than 3 .

\section{Relations among the teachers and among staffs, among students and students with staff:}

In this study it was found that Respondents' perception was negative about the items 'relationship among teachers', and 'relationship among students is good' and mean scores were 2.98 and 2.93 respectively. Present study found out that most of the students perceived that they had good friends in their institute and they never felt loneliness in their institute and their overall social life is fine in this institute, and mean scores of responses were more than 3 for each. Respondents' perception was positive about these aspects. Though mean score for the item, 'relationship among students is good' was below 3 but most of the respondents felt that they had good friends and they never felt loneliness and their overall social life is fine in this institute. Chandratilake (2009) and Abraham (2008) found that the students' perception was

Bangladesh Journal of Medical Education 2013;4(1):20-24. 
negative with a median score of responses less than 2 for item 'I seldom feel lonely'. But most of the respondents disagreed that staffs behave well with the students. Mean score for this item was 2.63. Lempp and Seale (2004) in their study found that 15 out of 23 clinical students mentioned that there were several reports of nurses and midwives treating medical students disrespectfully.

\section{Quality of teaching in their institute in terms of hidden curriculum:}

Respondents' perception was positive regarding the statement 'I am interested to attend the class; Teachers always take lecture class according to routine; Teachers always take class in the ward according to routine; Teachers are always sincere in teaching; Teaching time is used properly' and mean scores were more than 3 for each .Most of the students perceived that teachers were authoritarian and mean score for this item was 2.16. Chandratilake (2009) and Abraham (2008) found that the most of the students' perceived that teachers were authoritarian. Most of the students perceived negatively about "Atmosphere is relaxed in all lecture classes; Atmosphere is relaxed in classes in ward' with means less than 3. Chandratilake (2009) found that the most of the students' perceived that the atmosphere during ward teaching is relaxing. Most of the respondents perceived that they learned enough about empathy, became more patient, and more disciplined after coming in this institute. Similarly Abraham (2008) found in his study that most of the students learned a lot about empathy in their profession. Most of the students perceived that the never feel courage to ask question in classes when they did not understand and mean score for this item was 2.2. Abraham (2008) found similar result in his study.

\section{Teachers as a role model:}

It was found in this study that students' perceptions about the item 'Each teacher in this institute is a positive role model' was negative and mean score is 2.97 . But the most of the students 'perception was positive in case of item 'The role of a teacher as a role model is crucial for students to be a good doctor; and mean scores were more than three. Students understand the importance of teachers as a role model.

\section{Conclusion}

In this study it was found that perceptions of the respondents were either positive or negative about 43 items on different aspect of hidden curriculum which means the some issues on these item areas were satisfactory and some issues on these item areas were non satisfactory in their institutes. Different countries were exploring hidden curriculum in their medical institutes. Negative areas need attention of the teachers. It is important to sensitize and aware the concerned teachers/ authorities for valuing the importance of hidden curriculum. They will identify the areas of hidden curriculum in their institute and address the issues accordingly.

\section{References}

1. Abraham R, Ramnarayan K, Vinod P, Sharmila T., 2008. Students' perception of learning environment in an Indian medical school. BMC Medical Education $8: 20$

2. Chandratilake MN, Silva NR, 2009. Identifying poor concordance between the 'planned ' and the ' hidden' curricula at the time of curriculum change in a Sri Lanka medical school using the Dundee Ready education Environment Measure. South East Asian Journal of Medical Education 3(2): pp15-19

3. Chuang AW, Nuthalapaty FS, Casey PM , Kaczmarczyk JM, Cullimore AJ, Dalrymple JL, Dugoff L, Espey EL, Hammoud MM, Hueppchen NA, Katz NT, Peskin EG, 2010. To the point: reviews in medical education taking control of the hidden curriculum. American Journal of Obstetrics and Gynaecology October 2010:316.e1-6

4. Cruess SR, Cruess RL, Steinert Y, 2008. Role modeling making the most of a powerful teaching strategy. BMJ336: pp 718-721

5. Hafferty FW, 1998. Beyond curriculum reform: confronting medicine's hidden curriculum. Academic medicine Apr, 73(4): pp 403-407

6. Haidet P, Stein HF, 2006. The role of student teacher relationship in the formation of physicians, The hidden curriculum as process. J Gen Intern Med 21:pp S16-20

7. Harden MR,2001(b) AMEE guide no 21: curriculum mapping : a tool for transparent and authentic teaching and learning Medical Teacher, 23(2) p123-137

8. Harden MR, 2005. Chapter 2 curriculum planning and development, A practical guide for medical teachers, $2^{\text {nd }}$ edition, Harcourt publishers Ltd, Elsevier limited

9. Harden RM, 1986. Ten questions to ask when planning a course or curriculum. Medical Education 20: pp356365

10. Hutchinson L, 2003. Educational environment, $A B C$ of teaching and learning in Medicine. BMJ 326:12 $2^{\text {th }}$ April

11. Kommalage M, 2011. Hidden and informal curriculum in medical schools: impact on the medical profession in Sri Lanka. Ceylon Medical Journal 56: pp 29-30

12. Lempp H,Seale C, 2004. The hidden curriculum in under graduate medical education: qualitative study of medical students 'perception of teaching'. BMJ 329: pp 770-773.

13. Lamiani G, leone D, meyer EC, Moja EA, 2011. How Italian students learn to become physicians: A qualitative study of the Hidden curriculum. Medical teacher 33: pp 989-996

14. Tekian A, 2009. Must the hidden curriculum be the black box for 'unspoken truth'? Medical Education 43: pp 822-823 